\title{
Study the extraction process and antibacterial activity in vitro of ethanol extract of grape leaves
}

\begin{abstract}
Purpose: To optimize the extraction process and to investigate antibacterial activity in vitro of ethanol extract of grape leaves.

Methods: The extraction was extracted successively with ethanol in a soxhlet apparatus and the antibacterial activity was assessed by $\mathrm{K}-\mathrm{B}$ agar disc diffusion method. The concentration of ethanol, temperature, time, solid-liquid ratio as factors for optimization. Escherichia coli, Staphylococcus aureus, Candida albicans, Bacillus subtilis as test organisms which used for antibacterial study and Staphylococcus aureus was choosed as the indicator organisms for the most obvious bacteriostatic effect. The optimized extraction process was established by using single-factor and orthogonal experiment, which was guided by the diameter of inhibition zone.
\end{abstract}

Results: Magnitude order of the effect of the four factors on extraction from grape leaves was ethanol concentration $>$ extraction temperature $>$ solid-liquid ratio>extraction time. The best extraction condition as follows: $70 \%$ ethanol as extractant, extraction temperature 70 , ratio of material to liquid 1:30, extraction time $3 \mathrm{~h}$. The order of bacteriostasis of ethanol extract of grape leaves was Staphylococcus aureus $>$ Escherichia coli $>$ Candida albicans $>$ Bacillus subtilis.

Conclusion: The ethanol extract of grape leaves had significant antibacterial activity for Staphylococcus aureus and Escherichia coli, especially Staphylococcus aureus, while had no significant antibacterial activity for Bacillus subtilis. The optimized extraction process was established by this paper can be used to extract anti-bacterial substances and it has the advantages of fast speed, easy operation and environmental protection.

Keywords: grape leaves, ethanol extract, extracting technology, orhogonal experiment
Volume 2 Issue 2 - 2018

\author{
Yan Zhang,' Korbanjhon Brad, ${ }^{2}$ Ning Zhang, ${ }^{2}$ \\ Qingfeng Yang, ${ }^{2}$ Xiaoyu Liu ${ }^{2}$ \\ 'Department of Food Nutrition and Safety, Tianjin University of \\ Science and Technology, China \\ ${ }^{2}$ Department of Xinjiang Uygur Autonomous Region, Yili \\ Normal University, China
}

Correspondence: Yan Zhang, Department of Food Nutrition and Safety, Tianjin University of Science and Technology, China, Email cpzyyan@I26.com

Received: March 26, 2018 | Published: April 10, 2018

\section{Introduction}

Grape (Vitu Vinifera L.), one of the world's oldest plants, is the Vitaceae vitis deciduous vines. Grapes are grown in most parts of China, especially in Xinjiang., ${ }^{1,2}$ Grape leaves are used as Chinese Traditional Medicinal Materials, curing vomiting, edema, urination, red eyes and other symptoms. According to literatures, grape leaves contain abundant flavonoids with high physiological activity, and organic acid, tannins, oligomeric stilbenes, etc. Grape leaves are mostly used as cooking materials in Turkey, Greece and the Middle East area, one of the most famous dishes is the domasi, a dish with rice and meat in grape leaves. ${ }^{2-5}$ The grape plant resources are rich in China, but a lot of grape leaves have not yet been fully developed and used. Plant extracts from 73 species of 29 families of vegetables, flowers, trees, field crops and weeds were selected to test their antibacterial activity by Zhou Xuan. The experiment indicated that leaf extracts of Grape leaves had strong antibacterial activity. ${ }^{6,7}$ In this paper, ethanol extract of grape leaves were extracted using $70 \%$ ethanol as the extractant, and the optimum extraction conditions were found by orthogonal test based on single factor experiments, and the antibacterial activity of ethanol extract of grape leaves in vitro were determined. It will provide scientific basis for the extraction and utilization of anti-bacterial substances in grape leaves.

\section{Experimental}

\section{Materials and chemicals}

Grape leaves collected in September 18, 2013 from kale township of Turpan City, dried naturally,then drying on the electric heating temperature drying box at the temperature of $40^{\circ} \mathrm{C}$ to avoid light, crushing, stored at $40^{\circ} \mathrm{C}$. The collected material was authenticated by Prof. Korbanjhon Brad, Key Laboratory at Universities of Education. Department of Xinjiang Uygur Autonomous Region, Yili Normal University. Staphylococcus aureus, Bacillus subtilis, Escherichia coli, Canidia Albicans were purchased from Beijing Lai Yiu biological science and Technology Co Ltd. Beef extract peptone agar medium, LB medium, potato culture medium were purchased from Hangzhou microbial reagent limited company. Agar powder, peptone were purchased from Tianjin city Yingbo biochemical reagent Co. Ltd. Beef extract was purchased from Beijing aoboxing biotechnology limited liability Company. Glucose purchased from Tianjin Tianxin fine chemical development center. Anhydrous ethanol (A.R.) purchased from Chengdu Kelong Chemical Reagent factory. The remaining reagents were analytically pure.

\section{Preparation of sample solution}

Grape leaves was dried on the electric heating temperature drying 
box at the temperature of 50, crushed, Screened through mesh size of 60 , then the powder was weighed accurately to $250 \mathrm{~mL}$ Soxhlet extractor, submerged under $75 \%$ ethanol $(1: 20, \mathrm{~g} / \mathrm{mL})$, and refluxed $3.5 \mathrm{~h}$ at 80 . Ethanol can be recovered through reduced pressure distillation, and then ethanol extract of grape leaves was obtained after vacuum drying. The extraction were transferred to a $10 \mathrm{ml}$ volumetric flask, diluted with sterile water, left in fridge at 4.

\section{Determination of antibacterial activity in vitro}

\section{Inhibition of bacteria (K-B agar disc diffusion method)}

$10 \mu \mathrm{L}$ the cultured bacteria suspension was added to a Petri dish with beef extract peptone solid culture medium under sterile conditions, coated evenly with sterile triangular glass. According to the aseptic operation requirement, the predried and sterilization filter paper flats $(6.0 \mathrm{~mm})$ were dip in grape leaf ethanol extract, then paste on bacteria containing medium, each plate 3 filter paper flats, spaced a certain distance and triangular shaped arrangement, one of the three was blank control. The tests were repeated 3 times. The prepared plates were put into the incubator at 37 , for $24 \mathrm{~h}$, and then observed and the diameter of inhibition zone was measured.

\section{Inhibition of fungoid (K-B agar disc diffusion method)}

Under sterile conditions, $10 \mu \mathrm{L}$ the cultured fungoid suspension absorbs added to the culture dish with PDA culture medium, coated evenly with sterile triangular glass. According to the aseptic operation requirement, the predried and sterilization filter paper flats $(6.0 \mathrm{~mm})$ were dip in grape leaf ethanol extract, then paste on bacteria containing medium, there were 2 filter paper flats which were dip in ethanol extract of grape leaves dispersed on each plate with tweezer, 1 filter paper flats which was dip in sterile water as the blank control. The tests were repeated 3 times. The prepared plates were put into the incubator at $28^{\circ} \mathrm{C}$, for $24 \mathrm{~h}$, and then observed and the diameter of inhibition zone was measured.

\section{Optimization of the ethanol extraction technology of grape leaves}

\section{Single factor test}

The grape leaves were collected a number of copies (each about $2 \mathrm{~g}$ ), to $250 \mathrm{~mL}$ Soxhlet extractor, then treated with different concentrations of ethanol as extracting agent. The effects of ethanol concentration, extraction time, extraction temperature and solid-liquid ratio on extraction rate and antibacterial activity of total flavonoids in

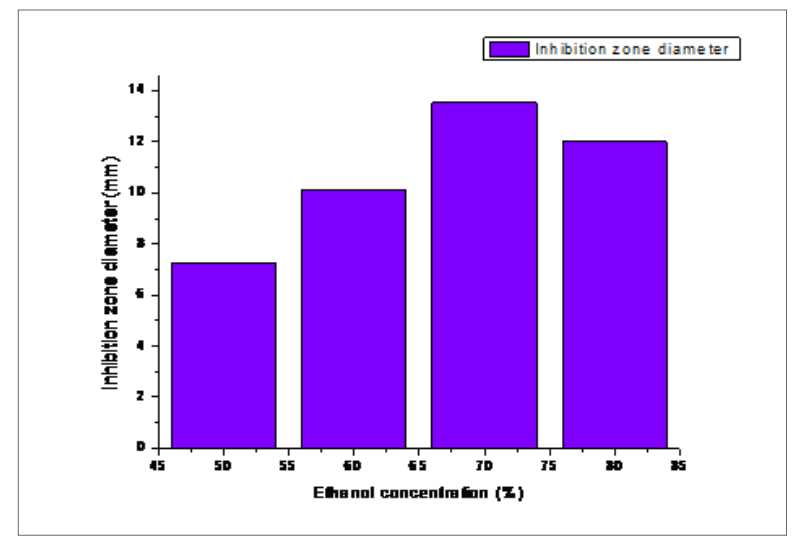

Figure I Effect of concentration of ethanol on inhibitory effect grape leaves were investigated respectively, taking the diameter of bacteriostatic circle as index.

\section{Orthogonal test}

Four most influential factors were selected based on single factor experiment and an $\mathrm{L}_{9}\left(3^{4}\right)$ orthogonal test were

designed. The analysis is able to determine the primary and secondary relations of various factors affecting bacteriostasis experiment and the optimal extracting technological conditions were identified. Under the optimum conditions, the test organisms which contains Escherichia coli, Staphylococcus aureus, Candida albicans, and bacillus subtilis were used to antibacterial test by $\mathrm{K}-\mathrm{B}$ agar disc diffusion method, then the result of antibacterial test was compared.

\section{Results}

The results of single factor test effect of concentration of ethanol on inhibitory effect Grape leaf powder were weighed accurately (each $2 \mathrm{~g}$ ), placed in a Soxhlet extractor. According to the material liquid ratio of 1:30, ethanol solution were added, the concentration were $50 \%, 60 \%, 70 \%, 80 \%$, respectively. The extraction lasted for $3 \mathrm{~h}$, at $70^{\circ} \mathrm{C}$. The remaining extract was vacuum concentrated through rotary evaporation, the ethanol recovery. The dried extract dissolved in $5 \mathrm{ml}$ sterile water. The four kinds of extraction solution were used in the bacteriostatic test for Staphylococcus aureus respectively. The results were shown in Table 1, Figure1 and Figure 2. Effect of concentration of ethanol on inhibitory effect From Figure 1, with the increase of ethanol concentration, the bacteriostatic activity of ethanol extract of grape leaves increased first, and then decreased. when the concentration of ethanol was $70 \%$, the average diameter of inhibitory zone increased to a peak value, $13.54 \mathrm{~mm}$, when more than $70 \%$, the bacteriostatic activity declined. As the concentration of ethanol increased, fat soluble substances dissolution increased, it could be the reason that the bacteriostatic activity changed. Therefore, the proper ethanol concentration was $70 \%$.

Table I Effect of concentration of ethanol on inhibitory effect

\begin{tabular}{lllll}
\hline \multirow{2}{*}{$\begin{array}{l}\text { Ethanol } \\
\text { Concentration }\end{array}$} & \multicolumn{4}{c}{ Inhibitory Zone Diameter $(\mathrm{mm})$} \\
\cline { 2 - 5 }$(\%)$ & $\mathrm{I}$ & $\mathbf{2}$ & $\mathbf{3}$ & $\begin{array}{l}\text { Average } \\
\text { Diameter }\end{array}$ \\
\hline 50 & 7.32 & 6.70 & 7.70 & 7.24 \\
60 & $11.7 \mathrm{I}$ & 12.22 & 6.43 & 10.12 \\
70 & 14.06 & 13.85 & 12.72 & 13.54 \\
80 & 12.21 & 12.31 & $11.5 \mathrm{I}$ & 12.01 \\
\hline
\end{tabular}

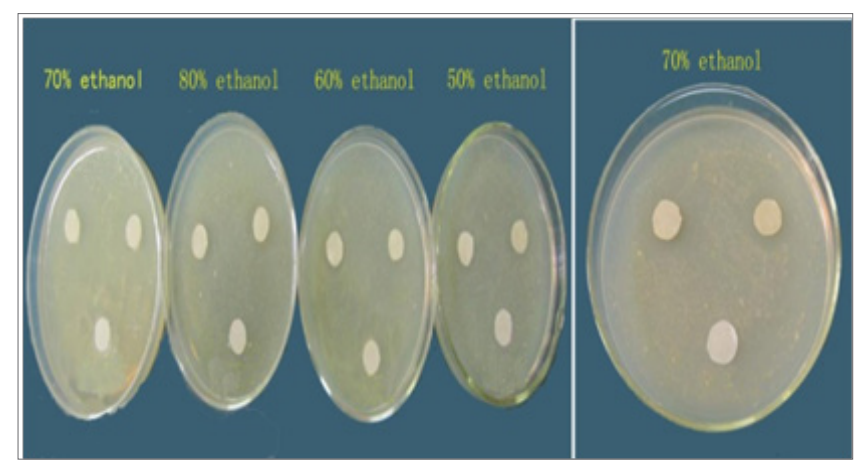

Figure 2 Effect of concentration of ethanol on inhibitory effect 


\section{Effect of ratio of material to liquid on bacteriostasis effect}

Grape leaf powder were weighed accurately (each $2 \mathrm{~g}$ ), placed in a Soxhlet extractor. The material liquid ratio is 1:20, 1:30, 1:40, 1:50 respectively, $70 \%$ ethanol solution were added. The extraction lasted for $3 \mathrm{~h}$, at $70^{\circ} \mathrm{C}$. The bacteriostatic effect on Staphylococcus aureus of the four kinds of extraction solution were shown in Table 2 and Figure 3. As seen in Figure 4, the size of inhibition zone increases gradually with the ratio of material to liquid, the most obvious bacteriostasis effect of ratio of material to liquid is 1:50 (diameter of inhibition zone $13.27 \mathrm{~mm}$ ). It can be seen in Figure 5, when the ratio of material to liquid is 1:20, the bacteriostatic activity of ethanol extract of grape leaves was low, it may be explained that when ratio of material to liquid is low, the solvent was not enough to dissolve the substance which have antibacterial activies. When the ratio of material to liquid is $1: 30$ to $1: 50$, the average diameter of inhibition zone shows no significant difference. When the ratio of material to liquid is $1: 30$, the effect of extraction is good enough, the increase of the amount of solvent has no significant effect on the antibacterial activities. Taken the production cost in consideration, the best ratio of material to liquid is $1: 40$.

Table 2 Effect of ratio of material to liquid on bacteriostasis effect

\begin{tabular}{lllll}
\hline \multirow{2}{*}{$\begin{array}{l}\text { Solid-Liquid } \\
\text { Ratio (G/MI) }\end{array}$} & \multicolumn{4}{l}{ Inhibitory Zone Diameter $(\mathbf{m m})$} \\
\cline { 2 - 5 } & $\mathbf{I}$ & $\mathbf{2}$ & $\mathbf{3}$ & $\begin{array}{l}\text { Average } \\
\text { Diameter }\end{array}$ \\
\hline $\mathrm{I}: 20$ & $9.7 \mathrm{I}$ & $\mathrm{I} 1.32$ & $9.5 \mathrm{I}$ & 10.18 \\
$\mathrm{I}: 30$ & 13.32 & 13.38 & 12.86 & 13.19 \\
$\mathrm{I}: 40$ & 13.40 & 13.28 & 12.96 & 13.21 \\
$\mathrm{I}: 50$ & $13.4 \mathrm{I}$ & $\mathrm{I} 3.15$ & 13.24 & 13.27 \\
\hline
\end{tabular}

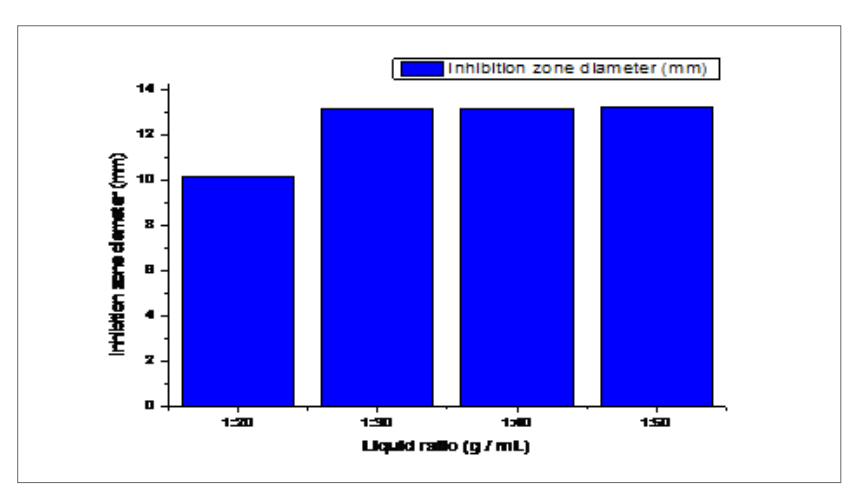

Figure 3 Effect of ratio of material to liquid on bacteriostasis effect

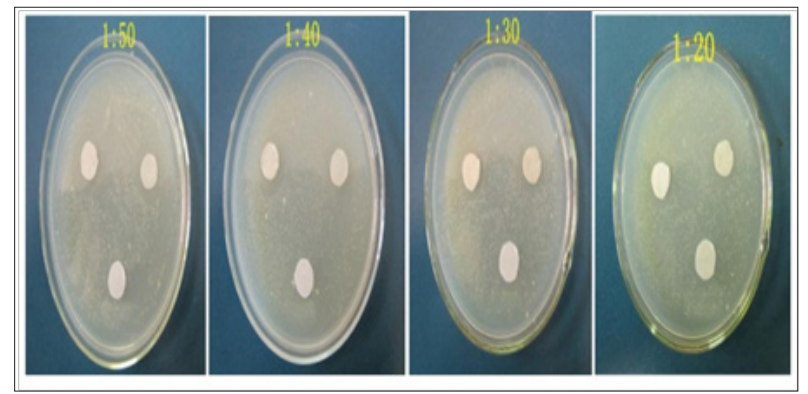

Figure 4 Effect of ratio of material to liquid on bacteriostasis effect

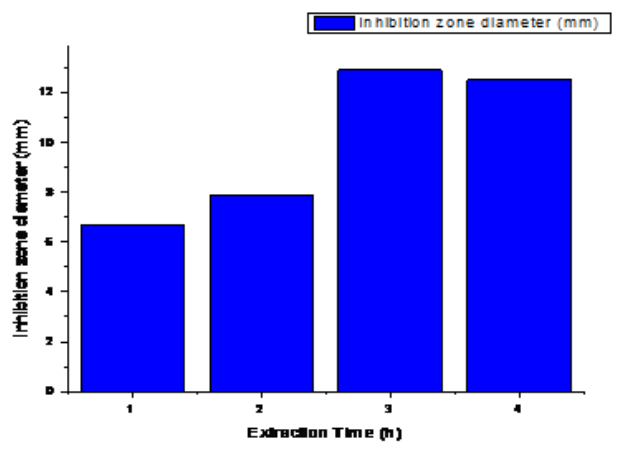

Figure $\mathbf{5}$ The influence of extraction time on bacteriostasis effect

\section{The influence of extraction time on bacteriostasis} effect

Grape leaf powder were weighed accurately (each $2 \mathrm{~g}$ ), placed in a Soxhlet extractor. The material liquid ratio is $1: 30$, and $70 \%$ ethanol solution was added. The extraction time was $1 \mathrm{~h}, 2 \mathrm{~h}, 3 \mathrm{~h}, 4 \mathrm{~h}$ respectively. The bacteriostatic effect on Staphyloccocus aureus of the four kinds of extraction solution were shown in Table 3 and Figure 6. It can be seen in Figure 6, with the extraction time increased, antibacterial activie of the extract of grape leaves increased firstly and then decreased. When the extraction time was $3 \mathrm{~h}$, the average diameter of inhibitory zone was $12.91 \mathrm{~mm}$, and the ability of the extract restraining bacterium was best. When the extraction time was less than $3 \mathrm{~h}$, the extract had no obvious bacteriostatic effect, which may be explained that when the heating time was too short, the substance with antibacterial activie was not extracted enough, and when it was longer than $3 \mathrm{~h}$, there was a downward trend for the antibacterial activity of the ethanol extract of grape leaves. This could be because that some ethanol evaporated, making the boiling point of the solvent increase and some substance with antibacterial activie may be damaged, reducing the bacteriostatic activity. To sum up, $3 \mathrm{~h}$ was the extraction time we chose.

Table 3 The influence of extraction time on bacteriostasis effect

\begin{tabular}{lllll}
\hline \multirow{2}{*}{$\begin{array}{l}\text { Extraction } \\
\text { Time }(\mathbf{H})\end{array}$} & \multicolumn{4}{c}{ Inhibitory Zone } \\
\cline { 2 - 5 } & $\mathbf{1}$ & $\mathbf{2}$ & $\mathbf{3}$ & $\begin{array}{l}\text { Average } \\
\text { Diameter }\end{array}$ \\
\hline $\mathrm{I}$ & 6.40 & 6.12 & 7.56 & 6.69 \\
2 & 7.92 & 8.31 & 7.38 & 7.87 \\
3 & 13.35 & 12.93 & 12.44 & 12.91 \\
4 & 11.81 & 13.58 & 12.20 & 12.53 \\
\hline
\end{tabular}

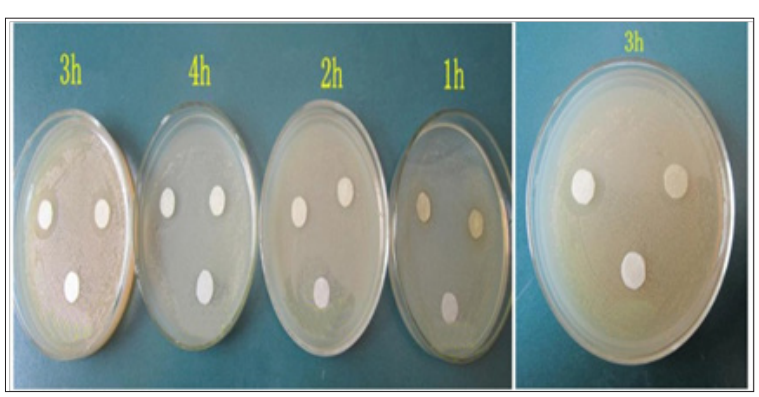

Figure $\mathbf{6}$ The influence of extraction time on bacteriostasis effect 
The influence of extraction temperature on antibacterial effect

Grape leaf powder were weighed accurately (each $2 \mathrm{~g}$ ), placed in a Soxhlet extractor. The material liquid ratio is $1: 30$, and $70 \%$ ethanol solution was added. The extraction temperature was $50^{\circ} \mathrm{C}-80^{\circ} \mathrm{C}$ respectively. The bacteriostatic effect on Staphyloccocus aureus of the four kinds of extraction solution were shown in Table 4 and Figure 7. As can be seen from Table 5, with the extraction temperature increased, antibacterial activie of the extract of grape leaves first increased and then decreased. $70^{\circ} \mathrm{C}$ was best for the bacteriostasis effect (average diameter of inhibition zone $13.86 \mathrm{~mm}$ ). When the temperature ranged from $50^{\circ} \mathrm{C}$ to $60^{\circ} \mathrm{C}$, with the increase of temperature, the Table 4 The influence of extraction temperature on antibacterial effect

\begin{tabular}{lllll}
\hline \multirow{2}{*}{$\begin{array}{l}\text { Extraction } \\
\text { Temperature }\left({ }^{\circ} \mathrm{C}\right)\end{array}$} & \multicolumn{4}{c}{ Inhibitory Zone Diameter $(\mathbf{m m})$} \\
\cline { 2 - 5 } & $\mathrm{I}$ & 2 & 3 & $\begin{array}{l}\text { Average } \\
\text { Diameter }\end{array}$ \\
\hline 50 & 6.32 & 7.51 & 6.80 & 6.88 \\
60 & 8.33 & 9.12 & 9.43 & 8.96 \\
70 & 14.75 & 14.38 & 12.45 & 13.86 \\
80 & 11.26 & 11.74 & 10.88 & 11.29 \\
\hline
\end{tabular}

antibacterial activitives increased. It may be explained that with the increase of temperature, the extraction process is influenced not only by dissolution effect but also by thermal effect. Higher temperature makes higher rate of extraction and better antiberaterial effect. When temperature was higher than $70^{\circ} \mathrm{C}$, the antiberaterial activity declined. It may be explained that when temperature was higher than $70^{\circ} \mathrm{C}$, some antibiotic substance's activity declined or lost. Taking into account the low boiling point of the ethanol solvent, volatilization at high temperature is aggravated which results in too high polarity in the whole solvent system, reduces the extraction effect and lowers the bacteriostat. So $70^{\circ} \mathrm{C}$ is chosen as the best extraction temperature according to the experiment results aforementioned.

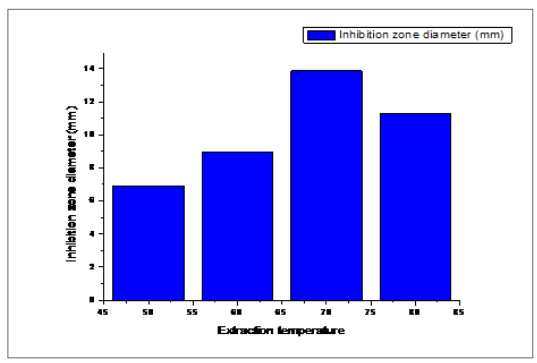

Figure 7 The influence of extraction temperature on antibacterial effect

Table 5 levels of factors

\begin{tabular}{lllll}
\hline Level & Extraction Temperature ${ }^{\circ} \mathrm{C}$ & Concentration of Ethanol (\%) & $\begin{array}{l}\text { Solid-Liquid Ratio } \\
(\mathbf{G} / \text { MI) }\end{array}$ & $\begin{array}{l}\text { Extraction } \\
\text { Time (H) }\end{array}$ \\
\hline & A & B & C & D \\
I & 60 & 60 & $1: 20$ & 2 \\
2 & 70 & 70 & $1: 30$ & 3 \\
3 & 80 & 80 & $1: 40$ & 4 \\
\hline
\end{tabular}

\section{Orthogonal test and the analyzing}

In the experiment, to comprehensively consider the process parameter of ethanol extraction, the concentration of ethanol, solidliquid ratio, extraction time and extraction temperature four factors were chosen ,because of cross influence among various factors . According to the results of single-factor test, the $\mathrm{L}_{9}\left(3^{4}\right)$ orthogonal test was done to optimize the extraction conditions. Nine groups of experimental data was analyzed, the visual result was showed in Table
6. Through the average and range analysis, magnitude order of the effect of the four factors on antibacterial activity in vitro of ethanol extract of grape leaves was: the concentration of ethanol>extraction temperature $>$ solid-liquid ratio $>$ reflux time. Based on the average of every factor in orthogonal test, the optimum extraction conditions were determined as $\mathrm{A} 2 \mathrm{~B} 2 \mathrm{C} 3 \mathrm{D} 2$ : the concentration of ethanol $(70 \%)$, extraction temperature $\left(70^{\circ} \mathrm{C}\right)$, solid-liquid ratio $(1: 40)$, the extraction time (3h).

Table 6 Results of orthogonal test nine groups of experimental data was analyzed, the visual result

\begin{tabular}{|c|c|c|c|c|c|}
\hline $\begin{array}{l}\text { Experiment } \\
\text { Number }\end{array}$ & $\begin{array}{l}\text { Extraction } \\
\text { Temperature }\end{array}$ & $\begin{array}{l}\text { Concentration } \\
\text { of Ethanol }\end{array}$ & $\begin{array}{l}\text { Solid-Liquid } \\
\text { Ratio }\end{array}$ & $\begin{array}{l}\text { Extraction } \\
\text { Time }\end{array}$ & $\begin{array}{l}\text { Inhibition Zone } \\
\text { Diameter (mm) }\end{array}$ \\
\hline & A & B & C & D & \\
\hline I & I & I & I & I & 11.3 \\
\hline 2 & I & 2 & 2 & 2 & 12.5 \\
\hline 3 & I & 3 & 3 & 3 & 12.1 \\
\hline 4 & 2 & I & 2 & 3 & 11.7 \\
\hline 5 & 2 & 2 & 3 & 1 & 13.6 \\
\hline 6 & 2 & 3 & I & 2 & 13.3 \\
\hline 7 & 3 & I & 3 & 2 & 12.8 \\
\hline 8 & 3 & 2 & 1 & 3 & 13 \\
\hline 9 & 3 & 3 & 2 & 1 & 11.9 \\
\hline average I & 11.97 & 11.93 & 12.53 & 12.27 & \\
\hline average 2 & 12.87 & 13.03 & 12.03 & 12.87 & \\
\hline average 3 & 12.57 & 12.43 & 12.83 & 12.27 & \\
\hline range & 0.93 & 1.11 & 0.87 & 0.64 & \\
\hline
\end{tabular}




\section{Antibacterial test under the optimum conditions}

Through the orthogonal experiment, the optimum conditions of extraction of grape leaves was obtained, and under these conditions, the ethanol extract of the grape leaves was extracted. Escherichia coli, Staphylococcus aureus, Bacillus subtilis, Candida albicans were used as test bacteria, using filter paper method and in strict accordance with the aseptic operation. The tests were repeated 3 times. The inhibition zone diameters of four kinds of bacteria were shown in Figure 8. It can be seen from Figure 9 and Figure 10 under the optimum conditions of extraction, magnitude order of the antibacterial effects of ethanolextract of grape leaves on four strains was: Staphylococcus aureus $>$ Escherichia coli $>$ Candida albicans $>$ Bacillus subtilis.

Table 7 antibacterial effect of ethanol extract of grape leaves under optimum conditions

\begin{tabular}{llcll}
\hline \multirow{2}{*}{ Strains } & \multicolumn{2}{l}{ Inhibition Zone Diameter $(\mathbf{m m})$} & $\begin{array}{l}\text { Average } \\
\text { Diameter }\end{array}$ \\
\cline { 2 - 4 } & $\mathbf{1}$ & $\mathbf{2}$ & $\mathbf{3}$ & 13.27 \\
\hline $\begin{array}{l}\text { Staphylococcus } \\
\text { aureus }\end{array}$ & 13.34 & 13.63 & 12.85 & 9.85 \\
$\begin{array}{l}\text { Escherichia coli } \\
\begin{array}{l}\text { Candida } \\
\text { albicans }\end{array}\end{array}$ & 9.51 & 9.82 & 10.22 & 8.16 \\
Bacillus subtilis & 7.22 & 7.71 & 8.14 & 7.05 \\
\hline
\end{tabular}

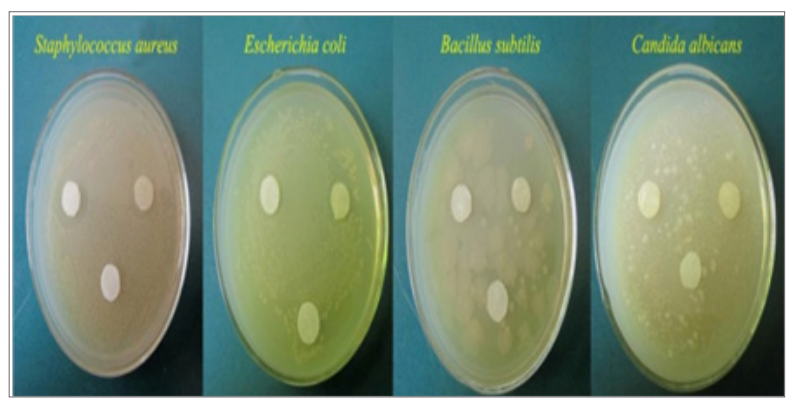

Figure 10 antibacterial effect of ethanol extract of grape leaves under optimum conditions

\section{Discussion}

There are many methods to extract natural products, but different extraction methods will have a certain impact on the experimental results. The purity of ethanol extract of grape leaves was rose by Soxhlet extraction method and it has low energy consumption. The Soxhlet extraction method directly heats the extraction agent, which fundamentally guarantees the rapid conduction and full use of energy. In addition, the extraction agent is recycled in. This not only reduces the amount of solvent, but also the operation time is shortened, then the energy consumption is greatly reduced; Ultrasonic extraction has a higher extraction rate and shorter extraction time than Soxhlet extraction. Different extraction solvents also make a difference to the extraction of active substance from grape leaves. The result which different concentration of ethanol was chose as the extractant suggested that the antibacterial activity was best when the concentration of ethanol was $70 \%$. Comparing with the test which using acetic ester as extractant the active substance has more oil, which have an effect on antibacterial active substance retains uncertain. Soxhlet extraction method was used in the extraction

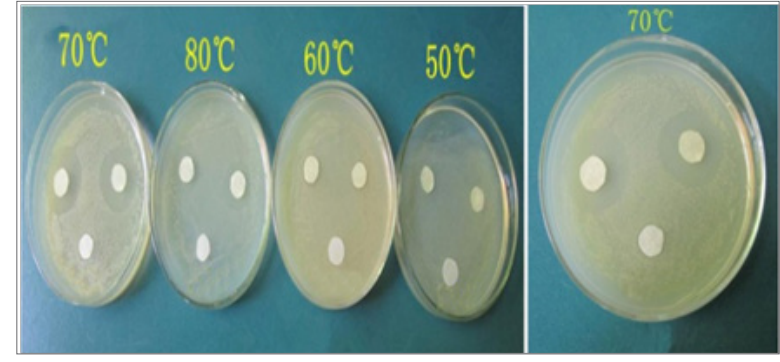

Figure 8 The influence of extraction temperature on antibacterial effect

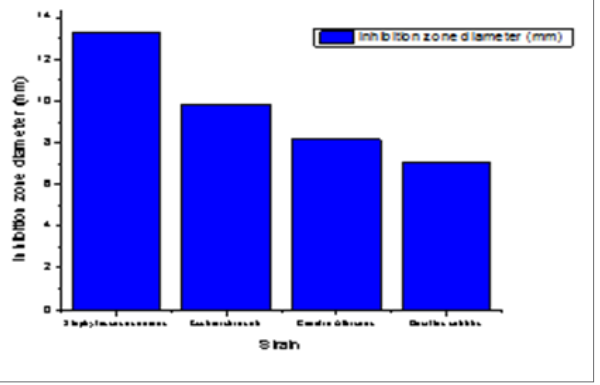

Figure 9 antibacterial effect of ethanol extract of grape leaves under optimum conditions

of active substance from grape leaves. The four factors, extraction temperature, ethanol Concentration, extraction time and Solid-liquid ratio, were taken into account in the extraction process. The extraction process should in appropriate temperature and time. High temperature or long extraction time could reduce the antibacterial activity. $70 \%$ ethanol concentration was chose as the best extractant by set ethanol concentration gradient. When less than $70 \%$, the antibacterial substance was not easy to obtain. But if more than $70 \%$, fat soluble substances dissolution increased, it has an effect on antibacterial effect. The extraction was incomplete if Solid-liquid ratio was too low. But ethanol was wasted if Solid-liquid ratio was too high. From the experimental process we found that, after stored 2-3 days, antibacteritial effect of grape leaves extract was not as well as fresh extract, which is likely to explain the instability of the active material, but it still require proof by further experimental research.

\section{Conclusion}

The ethanol extract of grape leaves had remarkable antibacterial effect on Staphylococcus aureus and Escherichia coli, and the biggest antibacterial activity on Staphylococcus aureus. But the antibacterial effect on Bacillus subtilis was not obvious. The order of antibacterial activities of ethanol extract from grape leaves on the four test organism was: Staphylococcus aureus $>$ Escherichia coli $>$ Candida albicans $>$ Bacillus subtilis.

\section{Acknowledgements}

We gratefully acknowledge Modern Analytical Technology Research Center of Tianjin University of Science and Technology for instrumental analysis. This project was supported by the Project of Key Laboratory at Universities of Education Department of Xinjiang Uygur Autonomous Region (No: 2013YSHXYB06) and the National Natural Science Foundation of China (21166024). 


\section{Conflict of interest}

The authors declared that no conflict of interest exists.

\section{References}

1. Zhang ZY, Peng Y. Study on the Optimum Extraction of Total Flavonoids from the Leaves of Grape. Biotechnology. 2007;17(6):58-60.

2. Mei-Na B, Li Z, Hong-Jin B, et al. Optimization of Extraction of Total Flavonoids from Cabernet Sauvignon Leaves by Response Surface Methodology. Agricultural Sciences. 2013;50(11):2037-2045.

3. Brad K, Yan Z, Liu W. Optimization of the Extraction of Flavonoids from Grape Leaves by Response Surface Methodology. Journal of the Chemical Society of Pakistan. 2013;35(4):1103-1105.
4. Sun L, Kang J, Zou J, et al. Development of grape leaves compound tea. Food Science and Technology. 2014;39(11):58-61.

5. Nilgun GB, Gulcan K. Evaluation of theantlradieal and anfio dant potential of grape extracts. Food Control. 2007;(18):1131-1136.

6. Yuan Q, Zhou B, Zhi-Pu LI. Effects of the extracts from Vitis amurensis leaves with different methods on Fusarium oxysporum fsp cucumerinum. Plant Protestion. 2009;35(2):125-127.

7. Zhou X, Zhou B, Zhi-Wen L, et al. Screening of plant extracts inhibit egg plant and Verticillium. Chinese Journal of Ecology. 2007;26(8):1217-1221. 